\title{
FAKTOR-FAKTOR YANG BERHUBUNGAN DENGAN PEMILIHAN DUKUN BERANAK SEBAGAI PENOLONG PERSALINAN PADA PESERTA JAMINAN KESEHATAN
}

\author{
Imelda Diana Marsilia \\ Program studi D III Kebidanan STIKes MITRA RIA HUSADA \\ imeldadiana33@yahoo.com
}

\begin{abstract}
ABSTRAK
Program Jaminan Kesehatan merupakan salah satu upaya dalam penurunan Angka Kematian Ibu (AKI) di Indonesia. Cakupan persalinan oleh tenaga kesehatan di Indonesia masih di bawah target yang diharapkan, termasuk di Kecamatan Babakan Madang Kabupaten Bogor yang hanya mencapai 66,4 \% tahun 2011. Cakupan persalinan oleh dukun beranak peserta jaminan kesehatan di Puskesmas Babakan Madang adalah 40\% pada tahun 2011. Tujuan penelitian ini untuk menganalisis faktor-faktor yang berhubungan dengan pemilihan dukun beranak sebagai penolong persalinan pada peserta jaminan kesehatan di wilayah kerja Puskesmas Babakan Madang Kabupaten Bogor. Metode Penelitian ini merupakan penelitian analitik dengan pendekatan Case Control. Penelitian dilakukan terhadap 122 orang ibu bersalin pada periode Juli sampai dengan Desember 2012 dibagi dalam 2 kelompok 61 orang kelompok kasus (dukun beranak) dan 61 orang kelompok kontrol (bidan). Analisis data menggunakan uji chi square dan uji regresi logistik ganda dengan tingkat kemaknaan $(\mathrm{p}<0,05)$, dan analisis PAR (population attributable risk). Hasil penelitian menunjukkan faktor yang berhubungan dengan pemilihan dukun beranak sebagai penolong persalinan secara signifikan adalah pengetahuan ibu $\mathrm{p}=0,003$, sikap $\mathrm{p}=0,007$, pendidikan ibu $\mathrm{p}=<0,001$, Sosial Budaya $\mathrm{p}=<0,001$, penghasilan keluarga $\mathrm{p}=<0,001$, dukungan suami $\mathrm{p}=0,018$ sedangkan keterjangkauan layanan, umur, paritas, pekerjaan tidak berhubungan ( $>0,05)$. Faktor dominan yang berhubungan dengan keputusan memilih penolong persalinan berdasarkan analisis multivariabel adalah sosial budaya $(\mathrm{OR}=5,644 ; 95 \% \mathrm{CI}=2,016-15,797)$. Penelitian ini memberikan kesimpulan bahwa pengetahuan, Sikap, pendidikan ibu, sosial budaya penghasilan keluarga dan dukungan suami yang tidak mendukung memilih dukun beranak sebagai penolong persalinan pada peserta jaminan kesehatan. Perlu dilakukan upaya peningkatan pengetahuan, pendidikan, dukungan suami dan sosial budaya yang mendukung serta pendidikan bidan gratis bagi anak dukun beranak.
\end{abstract}

Kata Kunci : Pemilihan penolong persalinan, Dukun beranak, Jaminan kesehatan

\section{PENDAHULUAN}

Pertolongan persalinan oleh tenaga kesehatan merupakan salah satu strategi dalam menangani masalah kesehatan ibu dan anak. Pemanfaatan pertolongan persalinan oleh bidan masih rendah dibandingkan dengan target yang diharapkan. Berbagai upaya telah dilakukan pemerintah untuk menurunkan AKI, diantaranya adalah program Safe Motherhood yang dilaksanakan sejak tahun 1988, pada tahun 2000 pemerintah mencanangkan Making Pregnancy Safer (MPS) yaitu suatu strategi untuk mengatasi berbagai penyebab kematian dan kesakitan ibu dan bayi. Program Perencanaan persalinan dan Pencegahan Komplikasi (P4K) dicanangkan pada tahun 2007 dalam upaya meningkatkan pelayanan terhadap ibu hamil agar melah irkan dengan aman dan selamat, namun kenyataannya penurunan AKI masih jauh dibawah target. ${ }^{1-4}$ Tingginya AKI di Indonesia dipengaruhi pula oleh rendahnya cakupan pemeriksaan selama kehamilan, belum memadainya cakupan persalinan oleh tenaga kesehatan dan sebanyak 70,6\% persalinan dilakukan di rumah yang tidak jarang jauh dari syarat bersih dan sehat serta rendahnya cakupan penanganan kasus obstetri. Terdapat hubungan yang positif antara cakupan persalinan oleh tenaga kesehatan dengan AKI, Semakin tinggi cakupan persalinan oleh tenaga kesehatan semakin rendah AKI. ${ }^{5}$ Masih rendahnya pemanfaatan jaminan kesehatan dan JAMPERSAL oleh ibu bersalin tentu akan terus berdampak buruk terhadap upaya penurunan AKI di masa yang akan datang dan masih banyak ibu-ibu tidak memanfaatkan perto longan persalinan oleh tenaga kesehatan sekalipun cakupan ANC di Puskesmas tinggi. 


\section{METODE}

Penelitian ini adalah analitik dengan metode Kasus kontrol (case control). Populasi dalam penelitian ini adalah seluruh ibu yang telah bersalin dalam periode 6 bulan yang lalu dan merupakan peserta jaminan kesehatan baik yang ditolong oleh tenaga kesehatan (Bidan) ataupun oleh dukun beranak dan bertempat tinggal menetap di wilayah kerja Puskesmas Babakan Madang dengan sampel 61 kelompok kasus dan 61 sampel kelompok kontrol. Pengumpulan data dilaksanakan pada tanggal Januari-Februari tahun 2013. Jenis data yang dipergunakan adalah data primer dengan instrumen pengumpulan data menggunakan kuesioner. Data yang terkumpul dilakukan uji analisis jalur.

\section{HASIL DAN PEMBAHASAN}

\section{Karakteristik subjek penelitian}

Tabel 1

Kesetaraan Karateristik subjek penelitian

\begin{tabular}{|c|c|c|c|c|c|c|}
\hline \multirow{3}{*}{$\begin{array}{c}\text { Karakteristik subjek } \\
\text { penelitian }\end{array}$} & \multicolumn{4}{|c|}{ Pemilihan Penolong Persalinan } & \multirow[t]{3}{*}{$\mathrm{X}^{2}$} & \multirow[t]{3}{*}{ Nilai $p^{*}$} \\
\hline & \multicolumn{2}{|c|}{$\begin{array}{l}\text { Kasus (Dukun } \\
\text { beranak) }\end{array}$} & \multicolumn{2}{|c|}{ Kontrol (Bidan) } & & \\
\hline & $\mathbf{n}$ & $\%$ & $\mathbf{N}$ & $\%$ & & \\
\hline \multicolumn{7}{|l|}{ Umur } \\
\hline - Berisiko & 16 & $26,2 \%$ & 12 & $19,7 \%$ & 0,742 & 0,389 \\
\hline - Tidak berisiko & 45 & $73,8 \%$ & 49 & $80,3 \%$ & & \\
\hline \multicolumn{7}{|l|}{ Paritas } \\
\hline - Berisiko & 19 & $31,1 \%$ & 20 & $32,8 \%$ & 0,038 & 0,846 \\
\hline - Tidak berisiko & 42 & $68,9 \%$ & 41 & $67,2 \%$ & & \\
\hline \multicolumn{7}{|l|}{ Pekerjaan } \\
\hline - Tidak Bekerja & 19 & $31,1 \%$ & 13 & $21,3 \%$ & 1,525 & 0,217 \\
\hline - Bekerja & 42 & $68,9 \%$ & 48 & $78,7 \%$ & & \\
\hline
\end{tabular}

*uji chi-square

Pada tabel 1 diatas yang menyajikan data karateristik usia, paritas dan pekerjaan, hasil statistik menyatakan bahwa tidak terdapat perbedaan yang bermakna $(p>0,05)$ dengan pemilihan penolong persalinan.

2. Faktor predisposisi dalam pemilihan dukun beranak sebagai penolong persalinan pada peserta Jaminan Kesehatan

Faktor predisposisi terdiri dari sub variabel pengetahuan, sikap, pendidikan dan sosial budaya. Untuk mengetahui adanya hubungan antara faktor predisposisi dan pemilihan dukun beranak sebagai penolong persalinan hasilnya dapat dilihat pada tabel 2 
Tabel 2

Faktor predisposisi dengan pemilihan dukun beranak sebagai penolong persalinan pada peserta Jaminan Kesehatan

\begin{tabular}{|c|c|c|c|c|c|}
\hline \multirow[b]{2}{*}{ Faktor Predisposisi } & \multicolumn{2}{|c|}{ Pemilihan Penolong Persalinan } & \multirow[b]{2}{*}{$\mathbf{X}^{2}$} & \multirow[b]{2}{*}{$\begin{array}{c}\text { Nilai } \\
\mathbf{P}\end{array}$} & \multirow[b]{2}{*}{ OR $(95 \%$ IK $)$} \\
\hline & $\begin{array}{c}\text { Kasus } \\
\text { (Dukun } \\
\text { Beranak) \% } \\
\end{array}$ & $\begin{array}{c}\text { Kontrol } \\
\text { (Bidan) } \\
\% \\
\end{array}$ & & & \\
\hline \multicolumn{6}{|l|}{ Pengetahuan } \\
\hline - Kurang & $57(93,4 \%)$ & $45(73,8 \%)$ & \multirow{2}{*}{8,612} & \multirow{2}{*}{0,003} & 5,067 \\
\hline - Baik & $4(6,6 \%)$ & $16(26,2 \%)$ & & & $(1,583-16,215)$ \\
\hline \multicolumn{6}{|l|}{ Sikap } \\
\hline - Negatif & $42(68,9 \%)$ & $25(40,9 \%)$ & \multirow{2}{*}{9,568} & \multirow{2}{*}{0,002} & 3,183 \\
\hline - Positif & $19(31,1 \%)$ & $36(59,1 \%)$ & & & $(1,512-6,701)$ \\
\hline \multicolumn{6}{|l|}{ Pendidikan } \\
\hline - Rendah & $43(70,5 \%)$ & $21(34,4 \%)$ & \multirow{2}{*}{15,907} & \multirow{2}{*}{0,000} & 4,550 \\
\hline - Tinggi & $18(29,5 \%)$ & $40(65,6 \%)$ & & & $(2,122-9,756)$ \\
\hline \multirow{2}{*}{\multicolumn{6}{|c|}{$\begin{array}{l}\text { Sosial } \\
\text { Budaya/Keyakinan }\end{array}$}} \\
\hline & & & & & \\
\hline \multirow{2}{*}{$\begin{array}{ll}\text { - } & \text { Tidak } \\
& \text { mendukung } \\
\text { - } & \text { Mendukung } \\
\end{array}$} & $48(78,7 \%)$ & $31(50,8 \%)$ & \multirow{2}{*}{10,379} & \multirow{2}{*}{0,001} & \multirow{2}{*}{$\begin{array}{c}3,573 \\
(1,618-7,890)\end{array}$} \\
\hline & $13(21,3 \%)$ & $30(49,2 \%)$ & & & \\
\hline
\end{tabular}

Keterangan: $\mathrm{x}^{2}=$ uji Chi Kuadrat

Dari hasil uji statistik menunjukkan bahwa dari empat sub variabel faktor predisposisi mempunyai hubungan $(\mathrm{p}<0,05)$ dengan pemilihan dukun beranak sebagai penolong persalinan yaitu sub variabel pengetahuan, sikap, pendidikan, sosial budaya.

Pengetahuan merupakan hasil tahu dan ini terjadi setelah orang melakukan penginderaan terhadap suatu objek tertentu, pengetahuan juga merupakan domain yang sangat penting untuk terbentuknya tindakan seseorang. ${ }^{6-10}$ menurut Green pengetahuan adalah faktor awal dari suatu perilaku yang diharapkan dan pada umumnya berkorelasi positif dengan perilaku,perilaku ibu dengan pengetahuan baik cenderung memanfaatkan tenaga kesehatan sebagai penolong persalinan begitu juga sebaliknya. Penelitian ini menunjukkan pengetahuan baik cenderung memanfaatkan tenaga kesehatan sebagai penolong persalinan, hal ini sesuai dengan penelitian di Zambia yang menunjukkan bahwa pengetahuan baik 2,5 kali memungkinkan ibu bersalin di layanan kesehatan dibandingkan dengan pengetahuan yang kurang $(95 \% \mathrm{CI}=1,2-5,4) .{ }^{11}$ Hasil penelitian yang berbeda di Tangerang menunjukkan ibu dari keluarga miskin yang pengetahuannya baik berpeluang memanfaatkan ASKESKIN sebesar 3,495 kali dibandingkan dengan ibu yang berpengetahuan kurang. ${ }^{12}$ Pengetahuan seseorang dapat dikaitkan dengan pendidikan. Hal ini terkait dengan peningkatan pengetahuan, penerimaan informasi, pola berfikir dan peningkatan harga diri serta percaya diri dalam mengambil keputusan.

Hasil penelitian menunjukkan bahwa hasil analisis bivariabel menunjukkan terdapat hubungan yang signifikan $(\mathrm{p}=0,002)$ antara sikap dengan pemilihan dukun beranak sebagai penolong persalinan, ibu dengan sikap negatif memilih dukun beranak sebagai penolong persalinan sebesar 3,183 kali dibandingkan bidan. Hal ini sesuai dengan beberapa penelitian terdahulu. Penelitian yang dilakukan di Aceh Tenggara dan di Tegal menyatakan terdapat hubungan yang signifikan antara sikap dengan keputusan penolong persalinan. Ibu yang mempunyai sikap negatif terhadap tenaga kesehatan kemungkinan bersalin dengan bidan menjadi lebih kecil. ${ }^{13-14}$ 
Sikap diartikan sebagai respon evaluatif. Respon hanya akan timbul apabila individu dihadapkan pada suatu stimulus yang menghendaki adanya reaksi individual. Sikap merupakan respon emosional seseorang terhadap suatu stimulus yang sifatnya adalah suatu evaluasi pribadi dari diri seseorang terhadap stimulus tersebut. Seseorang akan melakukan suatu perilaku jika dia memandang hal itu bersifat positif dan berguna bagi dirinya, akan tetapi apabila individu tersebut memandang hal itu bersifat negatif dengan kata lain tidak bermanfaat atau bahkan merugikan, maka dia akan menolak melakukannya. ${ }^{15}$

Hasil variabel pendidikan terdapat hubungan yang bermakna dengan $\mathrm{p}=0,000$ antara pendidikan dengan pemilihan dukun beranak sebagai penolong persalinan, ibu dengan pendidikan rendah cenderung 4,550 kali memilih dukun sebagai penolong persalinan dibandingkan dengan bidan. Hal ini mengindikasikan semakin tinggi pendidikan maka pengetahuan menjadi semakin tinggi sehingga kemungkinan memilih dukun beranak sebagai penolong persalinan juga semakin kecil dan akan beralih ke bidan, hal ini akan menjadi tantangan yang sangat besar untuk Kabupaten Bogor dan Kecamatan Babakan Madang khususnya dalam menurunkan angka kematian ibu karena dari data kependudukan menunjukkan populasi terbanyak ada pada pendidikan rendah, seperti diketahui bahwa kualitas sumber daya sangat ditentukan oleh kualitas ibu selain masalah status gizi termasuk juga masalah pendidikannya, pendidikan dipercaya mempunyai pengaruh terhadap kesadaran dan keinginan dalam mencari pelayanan kesehatan. Hasil penelitian ini juga sejalan dengan penelitian oleh Widianingsih di Banten menunjukkan faktor pendidikan berpengaruh pada pemilihan penolong persalinan, mayoritas berpendidikan rendah sekolah dasar dan sebagian lain tidak memiliki kesempatan untuk menyelesaikan sekolah. Sementara itu penelitian Liasuetrakul di Thailand menunjukkan pendidikan rendah merupakan faktor dominan wanita melahirkan dirumah, wanita cenderung membayar persalinan mereka sendiri, wanita menganggap asuransi kesehatan mereka tidak mengganti/menutupi biaya persalinan dan mereka memiliki kemauan yang kurang untuk mencari pelayanan kesehatan, penelitian Joshi di Singapore menunjukkan pendidikan yang rendah kurang dalam penggunaan asuransi kesehatan, hal ini berhubungan kuat dengan kepercayaan bahwa pelayanan kesehatan dapat di jangkau tanpa asuransi, demikian juga penelitian Langi di Sulawasi utara bahwa pendidikan ibu menjadi faktor penghambat dalam pemilihan pertolongan persalinan oleh tenaga kesehatan. ${ }^{16-18}$

Kepercayaan didalam masyarakat terhadap kesehatan ada yang dapat menunjang dan yang merugikan. Dalam hal ini masyarakat yang masih percaya dukun beranak sebagai penolong persalinan diperoleh secara turun temurun dan masyarakat masih terbiasa dengan cara-cara tradisional. ${ }^{19}$ Hasil penelitian ini juga sejalan dengan penelitian suharyanto di Tangerang menunjukkan proporsi kepercayaan ibu yang rendah atau tidak mendukung lebih besar pada kelompok ibu yang melahirkan di dukun beranak yaitu 41,35\% dibandingkan kelompok kontrol sebesar 9,3\%. Penelitian di Iran menunjukkan walaupun persalinan pada dukun beranak dapat memberikan rasa tenang dan nyaman serta mampu menolong dengan baik, namun hal ini akan menimbulkan risiko komplikasi yang mungkin timbul pada proses persalinan. ${ }^{20}$

Secara teoritis dukun beranak masih sangat berperan dalam etnos obstetri masyarakat karena sebagai berikut ia tinggal dekat membaur dengan warga setempat dan mudah dihubungi, dalam melakukan pekerjaannya tampil tidak formal, dan memiliki hubungan dekat dengan warga desa dan ibu hamil karena tampil berpembawaan diri 
tanpa jarak sosial secara psikologis, sentuhan-sentuhan tangannya kepada para ibu hamil dianggap mampu meminimalkan atau mereduksi gangguan fisik/sakit mereka pada saat hamil dan bersalin.

\section{Faktor pemungkin dalam pemilihan dukun beranak sebagai penolong persalinan pada peserta}

\section{Jaminan Kesehatan.}

Faktor pemungkin terdiri dari sub variabel keterjangkauan layanan dan penghasilan keluarga. Untuk mengetahui adanya hubungan antara faktor pemungkin dan pemilihan dukun beranak sebagai penolong persalinan hasilnya dapat dilihat pada tabel 3

Tabel 3

Hubungan antara faktor pemungkin dengan pemilihan dukun beranak sebagai penolong persalinan pada peserta jaminan kesehatan

\begin{tabular}{|c|c|c|c|c|c|}
\hline \multirow[b]{2}{*}{ Faktor Pemungkin } & \multicolumn{2}{|c|}{ Pemilihan Penolong Persalinan } & \multirow[b]{2}{*}{$\mathbf{X}^{2}$} & \multirow[b]{2}{*}{$\begin{array}{c}\text { Nilai } \\
\mathbf{p}^{*}\end{array}$} & \multirow[b]{2}{*}{$\begin{array}{c}\text { OR } \\
(95 \% \text { IK) }\end{array}$} \\
\hline & $\begin{array}{c}\text { Dukun beranak } \\
\text { (Kasus) } \\
\text { (n) } \%\end{array}$ & $\begin{array}{c}\text { Bidan } \\
\text { (Kontrol) } \\
\text { (n) } \%\end{array}$ & & & \\
\hline $\begin{array}{l}\text { Keterjangkauan } \\
\text { Layanan } \\
\text { Tidak terjangkau } \\
\text { Terjangkau }\end{array}$ & $\begin{array}{l}40(65,5 \%) \\
21(34,5 \%)\end{array}$ & $\begin{array}{l}38(62,3 \%) \\
23(37,7 \%)\end{array}$ & 0,142 & 0,706 & $\begin{array}{c}1,153 \\
(0,550-2,416)\end{array}$ \\
\hline $\begin{array}{l}\text { Penghasilan keluarga } \\
\text { Rendah } \\
\text { Tinggi }\end{array}$ & $\begin{array}{l}42(68,9 \%) \\
19(31,1 \%)\end{array}$ & $\begin{array}{l}19(31,1 \%) \\
42(68,9 \%)\end{array}$ & 17,344 & 0,000 & $\begin{array}{c}4,886 \\
(2,271-10,515)\end{array}$ \\
\hline
\end{tabular}

Keterangan: $\mathrm{x}^{2}=$ uji Chi Kuadrat

Dari hasil penelitian ini menunjukkan faktor pemungkin penghasilan keluarga ini memiliki hubungan $\mathrm{p}=0,000$ dengan pemilihan dukun beranak sebagai penolong persalinan. Penghasilan keluarga yang rendah atau dibawah UMR memiliki proporsi yang lebih besar OR 4,886 kali memilih dukun beranak sebagai penolong persalinan dibandingkan bidan. Hasil penelitian ini terlihat bahwa penghasilan keluarga dibawah UMR pada peserta jaminan kesehatan namun kenyataannya walaupun ekonomi kurang namun tidak memanfaatkan fasilitas persalinan gratis di pelayanan kesehatan. Meskipun rata-rata ibu sudah mengetahui tentang persalinan gratis menggunakan jaminan kesehatan, namun tetap ada sebagian ibu yang merasa khawatir melahirkan di bidan tetap mengeluarkan biaya. Kenyataan ini menggambarkan bahwa di Babakan Madang ibu ibu belum sepenuhnya memiliki keyakinan bahwa jaminan kesehatan akan menjamin sepenuhnya biaya persalinan, sehingga memutuskan tetap ke dukun beranak. Keterjangkauan layanan tidak berhubungan dengan pemilihan dukun beranak sebagai penolong persalinan dengan $\mathrm{p}=0,706$ atau lebih dari 0,05 . Hal ini mungkin jarak tempuh yang lebih jauh (lebih dari $3 \mathrm{~km}$ dan waktu yang ditempuh lebih dari 30 menit) akan lebih memudahkan memilih jangkauan pelayanan yang terdekat, karena kebutuhan waktu yang diperlukan lebih lama dan biaya transportasi juga lebih tinggi. Selain itu juga jarak dapat membatasi kemampuan dan kemauan ibu untuk mencari pelayanan terutama bila terbatasnya sarana transportasi. Pelayanan kesehatan di Puskesmas Babakan madang gratis bagi peserta jaminan kesehatan, tetapi peserta juga mengeluarkan biaya untuk transportasi ke tempat pelayanan kesehatan. Hal ini menunjukkan bahwa makin jauh jarak ke tempat pelayanan responden tidak akan memanfaatkan dan memilih penolong persalinan yang dekat dengan tempat tinggal. 


\section{Faktor penguat dalam pemilihan dukun beranak sebagai penolong persalinan pada peserta Jaminan}

\section{Kesehatan .}

Faktor penguat terdiri dari sub variabel dukungan suami untuk mengetahui adanya hubungan antara faktor pemungkin dan pemilihan dukun beranak sebagai penolong persalinan hasilnya dapat dilihat pada tabel 4 sebagai berikut.

Tabel 4

Hubungan antara faktor pemungkin dengan pemilihan dukun beranak sebagai penolong persalinan pada peserta jaminan.

\begin{tabular}{|c|c|c|c|c|c|}
\hline \multirow[b]{2}{*}{ Faktor penguat } & \multicolumn{2}{|c|}{ Pemilihan Penolong Persalinan } & \multirow[b]{2}{*}{$\mathbf{X}^{2}$} & \multirow[b]{2}{*}{$\begin{array}{c}\text { Nilai } \\
\text { p* }\end{array}$} & \multirow[b]{2}{*}{$\begin{array}{c}\text { OR } \\
(95 \% \mathrm{CI})\end{array}$} \\
\hline & $\begin{array}{c}\text { Dukun beranak } \\
\text { (Kasus) } \\
\text { (n) } \%\end{array}$ & $\begin{array}{c}\text { Bidan } \\
\text { (Kontrol) } \\
\text { (n) } \%\end{array}$ & & & \\
\hline \multicolumn{6}{|l|}{ Dukungan Suami } \\
\hline Tidak mendukung & $40(65,6 \%)$ & $27(44,3 \%)$ & 5,595 & 0,018 & 2,399 \\
\hline Mendukung & $21(34,4 \%)$ & $34(55,7 \%)$ & & & $(1,155-4,982)$ \\
\hline
\end{tabular}

Ibu yang mendapat dukungan dari suami baik cenderung memilih tenaga penolong oleh tenaga kesehatan, ibu sangat tergantung kepada keputusan suami, keadaan ini karena sebagian besar ibu berpendidikan rendah dan sangat menggantungkan hidupnya kepada suami dan adanya budaya patriarki. Selain itu kehidupan sosial budaya yang belum memperdayakan kaum wanita, sehingga tidak dapat melaksanakan keinginan sendiri jika belum mendapatkan persetujuan dari suami, hal ini sesuai dengan yang dikemukakan oleh teori Green dukungan keluarga merupakan faktor penguat terhadap perilaku pemanfaatan pelayanan kesehatan serta yang dikemukakan Becker untuk mendapatkan tingkat penerimaan yang benar tentang kerentanan, kegawatan dan keuntungan tindakan melawan atau mengobati penyakitnya diperlukan faktor-faktor eksternal antara lain nasehat atau anjuran kawan-kawan dan anggota keluarga lainnya.

5. Faktor dominan dalam pemilihan dukun beranak sebagai penolong persalinan pada peserta jaminan kesehatan.

Tabel 5

Analisis hubungan berbagai faktor dengan pemilihan dukun beranak sebagai penolong persalinan pada peserta jaminan kesehatan.

\begin{tabular}{llcccc}
\hline Model & \multicolumn{1}{c}{ Variabel } & $\begin{array}{c}\text { Koefisien } \\
\text { B }\end{array}$ & $\begin{array}{c}\text { S.E } \\
(\mathbf{B})\end{array}$ & $\begin{array}{c}\text { Nilai } \\
\mathbf{p}^{*}\end{array}$ & OR (IK 95\%) \\
& Pengetahuan & 1,413 & 0,745 & 0,058 & $4,110(0,955-17,684)$ \\
Model & Sikap & 1,150 & 0,487 & 0,018 & $3,158(1,217-8,196)$ \\
Akhir & Pendidikan & 1,470 & 0,485 & 0,002 & $4,350(1,680-11,258)$ \\
& Sosial Budaya & 1,731 & 0,525 & 0,001 & $5,644(2,016-15,797)$ \\
& Penghasilan keluarga & 1,417 & 0,509 & 0,005 & $4,124(1,521-11,183)$ \\
& Dukungan suami & 1,491 & 0,511 & 0,003 & $4,441(0,633-12,080)$ \\
& Konstanta & $-4,863$ & & & \\
\hline
\end{tabular}

Keterangan * uji regresi logistic

variabel yang paling dominan berpengaruh terhadap pemilihan dukun beranak sebagai penolong persalinan adalah sosial budaya. Kekuatan hubungan yang paling besar yaitu hubungan antara sosial budaya dengan pemilihan dukun beranak sebagai penolong persalinan dengan nilai OR 5,644, Artinya ibu dengan sosial budaya yang tidak mendukung memiliki risiko untuk memilih dukun beranak sebagai penolong persalinan sebesar 5,644 kali lebih besar dibandingkan ibu dengan sosial budaya mendukung. 
Selanjutkan dilakukan analisis PAR (population attributable risk) untuk mengetahui berapa besar proporsi pemilihan persalinan oleh dukun beranak pada populasi total bila faktor resiko dihilangkan, adapun hasilnya dapat dilihat pada tabel 6 berikut ini.

Tabel 6

Analisis (Population Attributable Risk) PAR pada variabel dominan sosial budaya, dengan Pemilihan Dukun beranak sebagai penolong persalinan pada peserta Jaminan Kesehatan

\begin{tabular}{lccc}
\hline \multicolumn{1}{c}{ Variabel } & $\begin{array}{c}\text { Dukun beranak } \\
\text { Kasus } \\
\text { n (61) }\end{array}$ & $\begin{array}{c}\text { Bidan } \\
\text { Kontrol } \\
\text { n (61) }\end{array}$ & $\begin{array}{c}\text { PAR* } \\
\text { \% }\end{array}$ \\
\hline $\begin{array}{l}\text { Sosial Budaya / Keyakinan } \\
\text { Tidak mendukung }\end{array}$ & 48 & 31 & 63 \\
Mendukung & 13 & 30 & \\
\hline * Rasio odds (a x d) / (bxc) & & & \\
PAR = p (r-1) \\
$\quad$ p(r-1) + 1
\end{tabular}

Didapatkan hasil $63 \%$ proporsi ibu yang memilih dukun beranak sebagai penolong persalinan dapat dicegah, bila sosial budaya yang tidak mendukung dihilangkan. Dan dilakukan analisis peluang regresi yang disajikan dalam tabel 7

Tabel 7

Peluang memilih dukun beranak sebagai penolong persalinan dari berbagai kombinasi faktor risiko

\begin{tabular}{|c|c|c|c|c|c|c|}
\hline Pengetahuan & Sikap & Pendidikan & Sosbud & $\begin{array}{c}\text { Penghasilan } \\
\text { Keluarga }\end{array}$ & $\begin{array}{c}\text { Dukungan } \\
\text { Suami }\end{array}$ & $\begin{array}{c}\text { Peluang } \\
\text { Dukun (\%) }\end{array}$ \\
\hline Rendah & Negatif & Rendah & $\begin{array}{c}\text { Tidak } \\
\text { mendukung }\end{array}$ & Rendah & $\begin{array}{c}\text { Tidak } \\
\text { mendukung }\end{array}$ & 99 \\
\hline Rendah & Negatif & Rendah & $\begin{array}{c}\text { Tidak } \\
\text { mendukung }\end{array}$ & Rendah & Mendukung & 99 \\
\hline Rendah & Negatif & Rendah & Tidak & Tinggi & Mendukung & 96 \\
\hline Rendah & Negatif & Rendah & $\begin{array}{l}\text { Mendukung } \\
\text { mendukung }\end{array}$ & Rendah & $\begin{array}{c}\text { Tidak } \\
\text { Mendukung }\end{array}$ & 95 \\
\hline Rendah & Negatif & Rendah & Mendukung & Tinggi & Mendukung & 84 \\
\hline Rendah & Negatif & Tinggi & Mendukung & Tinggi & Mendukung & 56 \\
\hline Rendah & Positif & Tinggi & Mendukung & Tinggi & Mendukung & 28 \\
\hline Tinggi & Positif & Tinggi & $\begin{array}{c}\text { Tidak } \\
\text { Mendukung }\end{array}$ & Tinggi & Mendukung & 35 \\
\hline Tinggi & Positif & Tinggi & Mendukung & Tinggi & Mendukung & 9 \\
\hline
\end{tabular}

Dari tabel diatas didapatkan hasil bahwa jika pengetahuan rendah, sikap negatif, pendidikan rendah, sosial budaya tidak mendukung, penghasilan keluarga rendah, dukungan suami tidak mendukung maka peluang untuk memilih dukun beranak sebesar 99\%, jika pengetahuan tinggi, sikap positif, pendidikan tinggi, sosial budaya mendukung, penghasilan keluarga tinggi, dukungan suami mendukung maka peluang untuk memilih dukun beranak sebesar $9 \%$.

\section{KESIMPULAN DAN REKOMENDASI}

Faktor predisposisi Pengetahuan, sikap, pendidikan, dan sosial budaya berhubungan dengan pemilihan dukun beranak sebagai penolong persalinan, Faktor pemungkin penghasilan keluarga berhubungan dengan pemilihan 
dukun beranak sebagai penolong persalinan. sedangkan keterjangkauan layanan kesehatan tidak berhubungan dengan pemilihan penolong persalinan, Faktor penguat dukungan suami berhubungan dengan pemilihan dukun beranak sebagai penolong persalinan, Sosial budaya merupakan faktor yang paling dominan berhubungan dengan pemilihan dukun beranak sebagai penolong persalinan pada peserta jaminan kesehatan. Saran nya yaitu Meningkatkan pengetahuan, pendidikan, dukungan suami, sosial budaya yang baik dan mendukung melalui penyuluhan dan pendidikan kesehatan kepada ibu dan ini merupakan tanggungjawab bersama dari berbagai pihak baik dari Dinas Kesehatan, Puskesmas, Aparat pemerintah dan peran serta masyarakat, menggalakkan penyuluhan kesehatan pada saat Antenatal care khususnya jaminan kesehatan dan manfaat bersalin dengan tenaga kesehatan dalam rangka peningkatan pengetahuan masyarakat dan melakukan pendekatan budaya dan adat istiadat kepada masyarakat agar bidan mudah diterima dan dimanfaatkan oleh masyarakat serta perlu adanya program pendidikan bidan di wilayah Kabupaten Bogor untuk anak dan cucu dukun beranak agar memutus mata rantai dan meningkatkan jumlah tenaga bidan.

\section{REFERENSI}

1. WHO. Modul Ajar Safe Motherhood. WHO Press; 2008. Hal 4-6

2. Manuaba IBG. Gawat darurat obstetri ginekologi dan obstetri ginekologi sosial untuk profesi bidan. Jakarta: EGC; 2008

3. Departemen Kesehatan Republik Indonesia. Rencana strategis nasional making pregnancy safer di Indonesia. Jakarta: Departemen Kesehatan RI; 2001.

4. Departemen Kesehatan Republik Indonesia. Pedoman praktis P4K dengan stiker. Jakarta: Departemen Kesehatan RI; 2008

5. Badan Penelitian dan Pengembangan Kesehatan. Riset Kesehatan Dasar Nasional (Riskesdas) 2010. Jakarta: Departemen Kesehatan RI; 2010

6. Notoatmodjo S. Ilmu perilaku kesehatan. Jakarta: Rineka Cipta; 2010.Hal 20

7. Anderson OW, Krathwohl DR. A taxonomy for learning, teaching and assessing: a revision of Bloom's taxonomy of educational objectives. New York: Longman; 2001. hlm. 27-31,66-89

8. Notoatmodjo S. Ilmu perilaku kesehatan. Jakarta: Rineka Cipta; 2010.hal 23-31

9. Notoatmodjo S. Promosi kesehatan dan ilmu perilaku. Jakarta: Rineka Cipta; 2007.hal 30-55

10. Stekelenburg J, Kyanamina S, Mukelabai M, Wolffers I, van Roosmalen J: Waiting too long: low use of maternal health services in Kalabo, Zambia.2004 [Diunduh 27 Desember 2012]. Tersedia dari: Wiley Online Library.http://onlinelibrary.wiley.com/doi/10.1111/j.1365-3156.2004.01202.x/full

11. Suharyanto H. Analisis Faktor-faktor yang berhubungan dengan pemanfaatan aseskin ibu keluarga miskin pada pelayanan kehamilan dan persalinan di puskesmas dan jaringannya di kota Tangerang tahun 2008. [tesis]. Jakarta: Unversitas Indonesia; 2008

12. Departemen Kesehatan Republik Indonesia. Rencana strategis nasional making pregnancy safer di Indonesia. Jakarta: Departemen Kesehatan RI; 2001. 
13. Musadad A, Rachmalina, Rahajeng E. Pengambilan keputusan dalam pertolongan persalinan di provinsi Nusa tenggara timur. NTT: Jurnal ekologi kesehatan vol 2 No. 1 April 2003: 200-208.

14. Winkjosastro H, Saifuddin. Ilmu Kebidanan. Jakarta: Yayasan Bina Pustaka Sarwono; 2008. Hal 101 115

15. Widyaningsih, Rachmawati T, Makowiecka K. Studi mengenai faktor penghalang dan penunjang rujukan yang efektif. Jakarta: Immpact Puska FKM Universitas Indonesia; 2007

16. Liabsuetrakul T, Oumudee N. Effect of health insurance on delivery care utilization and perceived delays and barriers among southern Thai women. 2011. [diunduh 26 Februari 2012] Tersedia dari: Biomed Central http://www.biomedcentral.com/1471-2458/11/510)

17. Langi.FG, Langi.G. Barriers to delivery care by skilled attendants in Sulawesi utara. 2009. Journal of Public and Development Vol.7 No.3 September-Desember 2009.

18. Joshi VD, Lim JFY. Health insurance in singapore: Who's not included and why, original article [Diunduh 10 Agustus 2012] Singapore Med J 2010; 51(5) : 399

19. Agustina N, Storeng K T, Filippi V, Wahdini M. Studi Etnografi: Konsekuensi kesehatan sosial dan budaya kehamilan dan kelahiran di Indonesia. Jakarta: Immpact Puska FKM Universitas Indonesia; 2007

20. Tabatabaie MG, Moudi Z, Vedadhir A: Home birth and barriers to referring women with obstetric complications to hospitals: a mixed-methods study Zahedan, Southeastern Iran.2012 [Diunduh 3 Februari 2012]. Tersedia dari Reproductive Health. http://www.reproduktive-healthjournal.com/content/9/1/5 